\title{
Real-World Clinical Outcomes Associated with Canagliflozin in Patients Aged 65 Years and Older with Type 2 Diabetes Mellitus in Spain: The Old Real-Wecan Study
}

\author{
Manuel A. Gargallo-Fernández ${ }^{1,2, *}$, Alba Galdón Sanz-Pastor ${ }^{2}$, Teresa Antón-Bravo ${ }^{3}$, Miguel Brito-Sanfiel ${ }^{4}$, \\ Jaime Wong-Cruz ${ }^{5}$ and Juan J. Gorgojo-Martínez ${ }^{5}$ D \\ 1 Department of Endocrinology and Nutrition, Hospital Universitario Infanta Leonor, 28031 Madrid, Spain \\ 2 Department of Endocrinology and Nutrition, Hospital Fundacion Jiménez Díaz, 28040 Madrid, Spain; \\ albagaldonsp@gmail.com \\ 3 Department of Endocrinology and Nutrition, Hospital Universitario de Móstoles, Móstoles, 28935 Madrid, \\ Spain; tantonb1978@gmail.com \\ 4 Department of Endocrinology and Nutrition, Hospital Universitario Puerta de Hierro, Majadahonda, \\ 28222 Madrid, Spain; mbritosanfiel@hotmail.com \\ 5 Department of Endocrinology and Nutrition, Hospital Universitario Fundación Alcorcón, Alcorcón, \\ 28922 Madrid, Spain; jemwong@fhalcorcon.es (J.W.-C.); juanjo.gorgojo@gmail.com (J.J.G.-M.) \\ * Correspondence: gargallomgar@gmail.com
}

Citation: Gargallo-Fernández, M.A.; Sanz-Pastor, A.G.; Antón-Bravo, T.; Brito-Sanfiel, M.; Wong-Cruz, J.; Gorgojo-Martínez, J.J. Real-World Clinical Outcomes Associated with Canagliflozin in Patients Aged 65 Years and Older with Type 2 Diabetes Mellitus in Spain: The Old Real-Wecan Study. Diabetology 2021, 2, 165-175. https://doi.org/10.3390/ diabetology2030015

Academic Editor: Peter Clifton

Received: 1 August 2021

Accepted: 30 August 2021

Published: 6 September 2021

Publisher's Note: MDPI stays neutral with regard to jurisdictional claims in published maps and institutional affiliations.

Copyright: (c) 2021 by the authors. Licensee MDPI, Basel, Switzerland. This article is an open access article distributed under the terms and conditions of the Creative Commons Attribution (CC BY) license (https:// creativecommons.org/licenses/by/ $4.0 /)$.
Abstract: The observational Real-Wecan study showed that canagliflozin $100 \mathrm{mg}$ (CANA100) as an add-on therapy, and canagliflozin 300 (CANA300), switching from prior SGLT-2i therapy, significantly improved several cardiometabolic parameters in patients with T2DM. The aim of this sub-analysis was to assess the effectiveness and safety of canagliflozin in patients aged $\geq 65$ years. The primary outcome of the study was the mean change in $\mathrm{HbA1c}$ over the follow-up period. A total of 583 patients met the inclusion criteria (39.5\% > 65 years), 279 in the cohort of CANA100 (36.9\% >65 years; mean $\mathrm{HbA} 1 \mathrm{c} 8.05 \%$ ) and 304 in the cohort of CANA300 (mean age 61.1 years; $41.8 \% \geq 65$ years; mean $\mathrm{HbA} 1 \mathrm{c} 7.51 \%)$. In the CANA100 cohort, older patients showed significant reductions in $\mathrm{HbA} 1 \mathrm{c}$ $(-0.78 \%)$ and weight $(-4.5 \mathrm{~kg})$. Patients aged $\geq 65$ years switching to CANA300 experienced a significant decrease in $\mathrm{HbA} 1 \mathrm{c}(-0.27 \%)$ and weight $(-2.1 \mathrm{~kg})$. There were no significant differences in $\mathrm{HbA} 1 \mathrm{c}$ and weight reductions when the cohorts of patients $<65$ and $\geq 65$ years were compared in a multiple linear regression model. The safety profile of canagliflozin was similar in both age groups. These findings support canagliflozin as an effective therapeutic option for older adults with T2DM.

Keywords: canagliflozin; SGLT-2 inhibitor; elderly patients; type 2 diabetes mellitus; real-world study

\section{Introduction}

Diabetes, particularly type 2 diabetes mellitus (T2DM), is becoming more prevalent in the general population, especially in individuals over the age of 65 years. Older patients with T2DM typically have a longer duration of disease, contributing to reduced pancreatic functioning, more comorbidities and greater medication complexity than those seen in younger people with T2DM. Hence, treatment of T2DM in older patients requires careful consideration of the increased risk of hypoglycaemia, cardiovascular and renal complications, frailty, and more serious drug-related adverse events (AE). Therefore, selection of any antihyperglycaemic agents (AHA) for treating these patients must consider the benefit/risk ratio. There are several current guidelines that specifically address the management of T2DM in this population to achieve glycaemic control with minimal risks [1-5].

Canagliflozin is one of the new therapies introduced in T2DM treatment in the last years. It belongs to the sodium-glucose co-transporter type 2 inhibitors (SGLT-2is) class of AHA drugs that reduce tubular reabsorption of filtered glucose, inducing urinary glucose excretion in individuals with hyperglycaemia, which leads to decreased plasma glucose 
as well as an osmotic diuresis and net caloric loss [6-9]. In phase 3 studies, canagliflozin has been shown, in patients with T2DM, to improve glycaemic control and reduce body weight and blood pressure (BP) in combination with different AHA therapies [10-14]. In addition, canagliflozin has demonstrated cardiovascular $(\mathrm{CV})$ and renal benefits in patients with T2DM and high CV risk or chronic kidney disease (CKD) $[15,16]$.

However, in most of these studies, the mean age of the population was below 65 years, so it is questionable to extend these results to older patients. In addition, no randomised clinical trials (RCTs) or real-world studies (RWS) have evaluated the possible outcome differences between the two age groups with the strategy of intensification of the SGLT-2i therapy by switching to CANA300, either from CANA100 or other SGLT-2is.

In summary, there is scarce data from RWS regarding the effectiveness and safety of canagliflozin comparing younger and older patients, and no data of the intensification of SGLT-2is therapy by switching to CANA300 in elderly patients with T2DM.

We have previously studied in a real-world setting the effectiveness of CANA100 and the switch to CANA300 from prior SGLT-2is in patients with T2DM [17]. In that study, we found significant improvement of several cardiometabolic parameters in patients with T2DM in a real-world setting, with a low incidence of AEs and a high rate of persistence, confirming the results from phase 3 RCTs with CANA100 and obtaining real-life evidence on the effectiveness and safety of switching to CANA300 from a prior SGLT-2i therapy in patients with suboptimal metabolic control. We performed a subanalysis, the oldaged patients real-world evidence with canagliflozin (Old Real-Wecan), of the previously multicentric retrospective study, to assess in a real-world setting the effectiveness and safety of CANA100 as a daily add-on to the background antihyperglycaemic therapy, and to evaluate the intensification of SGLT-2i therapy, by switching to CANA300 daily, either from CANA100 or other SGLT-2is, in patients of 65 years and older compared to younger individuals.

\section{Materials and Methods}

This subgroup analysis was based on data from the Real-Wecan study previously described [17]. Briefly, the Real-Wecan study is a multicentric retrospective study whose aims were to assess in a real-world setting the effectiveness and safety of canagliflozin $100 \mathrm{mg} / \mathrm{d}$ (CANA100) as an add-on to the background AHAs, and to evaluate the intensification of prior SGLT-2i therapy by switching to canagliflozin $300 \mathrm{mg} / \mathrm{d}$ (CANA300) in patients with T2DM. The patients (older than 18 years) were consecutively selected from the diabetes clinic databases.

Therapy with CANA100 or CANA300 was started at least 6 months before data collection and patients received at least 1 dose of the drug.

In patients with suboptimal $\mathrm{HbA1c}$ or weight response prior to SGLT-2is, switching to CANA300 was performed.

\subsection{Outcomes and Study Measures}

All data were obtained from medical records. Three visits were recorded: V1, baseline 1 (CANA100 mg) or switch (CANA300); V2, $6+2$ months after the start of CANA100 or after switching to CANA300; V3, last visit of the follow-up period.

Clinical parameters registered at baseline are shown in Table 1. At V1, V2, and V3: fasting plasma glucose (FPG), weight, Body Mass Index (BMI), systolic blood pressure (SBP), and diastolic blood pressure (DBP) were collected. Any death and all causes of withdrawals (WDs) were registered. AEs associated in clinical trials to SGLT-2is (Table 2) were collected at each visit. 
Table 1. Baseline characteristics of the patient cohorts by age group with canagliflozin $100 \mathrm{mg}$ (CANA100) and canagliflozin 300 mg (CANA300).

\begin{tabular}{|c|c|c|c|c|c|c|}
\hline & \multicolumn{2}{|c|}{ CANA100 } & \multicolumn{4}{|c|}{ CANA300 } \\
\hline & $\begin{array}{c}<65 \text { Years } \\
\text { (n 176) }\end{array}$ & $\begin{array}{c}\geq 65 \text { Years } \\
\quad(n \text { 103) }\end{array}$ & $p$ & $\begin{array}{c}<65 \text { Years } \\
\text { (n 177) }\end{array}$ & $\begin{array}{c}\geq 65 \text { Years } \\
\text { (n 127) }\end{array}$ & $p$ \\
\hline Follow-up period (months) * & $9.1(5.0-20.3)$ & $9.2(5.9-22.3)$ & 0.402 & $17.5(7.9-30.4)$ & $14.0(6.7-24.3)$ & 0.013 \\
\hline Gender (male/female) & $54 / 46$ & $56.3 / 43.7$ & 0.705 & $57.1 / 42.9$ & $54.3 / 45.7$ & 0.636 \\
\hline Age (years) & $52.8(10.0)$ & $71.5(4.9)$ & $<0.0001$ & $54.5(8.2)$ & $70.3(3.5)$ & $<0.0001$ \\
\hline Duration of T2DM (years) * & $8.0(3.7-13.4)$ & $12.0(8.4-17.8)$ & $<0.0001$ & $10.1(5.8-15.2)$ & $15.9(11.2-21.0)$ & $<0.0001$ \\
\hline $\mathrm{HbA} 1 \mathrm{c}(\%)$ & $8.11(1.60)$ & $7.94(1.40)$ & 0.375 & $7.48(1.24)$ & $7.55(0.93)$ & 0.572 \\
\hline Patients with $\mathrm{HbA} 1 \mathrm{c}>7 \%$ & 74.0 & 76.2 & 0.677 & 67.2 & 76.4 & 0.083 \\
\hline Fasting plasma glucose $(\mathrm{mg} / \mathrm{dL})$ & $167.1(61.8)$ & $156.8(49.1)$ & 0.131 & $144.4(38.1)$ & $142.6(32.9)$ & 0.664 \\
\hline Weight $(\mathrm{kg})$ & $99.2(22.1)$ & $87.5(16.9)$ & $<0.0001$ & $97.6(22.1)$ & $84.2(16.7)$ & $<0.0001$ \\
\hline $\mathrm{BMI}\left(\mathrm{kg} / \mathrm{m}^{2}\right)$ & $35.8(7.2)$ & $33.1(6.8)$ & 0.003 & $35.6(7.7)$ & $32.0(6.9)$ & 0.002 \\
\hline $\mathrm{SBP}(\mathrm{mmHg})$ & $137.8(20.3)$ & $139.7(20.0)$ & 0.485 & $136.3(13.7)$ & $135.2(15.6)$ & 0.560 \\
\hline $\mathrm{DBP}(\mathrm{mmHg})$ & $80.4(10.0)$ & $77.3(10.0)$ & 0.018 & $79.8(10.8)$ & $73.6(10.2)$ & $<0.0001$ \\
\hline eGFR $\left(\mathrm{mL} / \mathrm{min} / 1.73 \mathrm{~m}^{2}\right)$ & $92.4(14.3)$ & $76.6(15.0)$ & $<0.0001$ & $90.4(16.6)$ & $77.5(14.5)$ & $<0.0001$ \\
\hline Microalbuminuria $(\mathrm{mg} / \mathrm{g} \mathrm{Cr})$ * & $6.0(4.0-31.1)$ & $9.8(4.3-37.0)$ & 0.417 & $7.2(0-25.4)$ & $8.8(0-27.6)$ & 0.715 \\
\hline \multicolumn{7}{|l|}{ Diabetic renal disease (\%) } \\
\hline Stage G0/G1 & 67.9 & 24.7 & $<0.0001$ & 62.9 & 27.6 & $<0.0001$ \\
\hline Stage G3b & 0 & 1.0 & & 0.6 & 0 & \\
\hline Stage G4-G5 & 0 & 0 & & 0.6 & 0 & \\
\hline Stage A1 & 73.9 & 75.0 & 0.179 & 80.0 & 78.4 & 0.773 \\
\hline Stage A2 & 22.8 & 15.6 & & 16.8 & 19.6 & \\
\hline Stage A3 & 3.3 & 9.4 & & 3.2 & 2.1 & \\
\hline Hypertension & 68.2 & 82.5 & 0.009 & 81.9 & 85.8 & 0.365 \\
\hline Hypercholesterolaemia & 75.0 & 88.3 & 0.007 & 87.6 & 95.3 & 0.022 \\
\hline Hypertriglyceridaemia & 44.6 & 31.1 & 0.026 & 56.5 & 45.2 & 0.053 \\
\hline Combined hyperlipidaemia & 38.3 & 31.1 & 0.225 & 51.4 & 45.2 & 0.289 \\
\hline Diabetic renal disease & 18.8 & 24.3 & 0.273 & 26.6 & 29.1 & 0.62 \\
\hline Diabetic neuropathy & 7.4 & 8.7 & 0.686 & 8.5 & 15.7 & 0.05 \\
\hline Coronary artery disease & 8.0 & 9.8 & 0.597 & 5.6 & 17.3 & 0.001 \\
\hline Stroke & 2.8 & 5.8 & 0.216 & 3.4 & 3.9 & 0.801 \\
\hline Diabetic Retinopathy & 13.1 & 13.6 & 0.915 & 16.4 & 21.3 & 0.279 \\
\hline Peripheral artery disease & 1.7 & 5.8 & 0.06 & 6.8 & 12.6 & 0.084 \\
\hline
\end{tabular}


Table 1. Cont.

\begin{tabular}{|c|c|c|c|c|c|c|}
\hline & \multicolumn{2}{|c|}{ CANA100 } & \multicolumn{4}{|c|}{ CANA300 } \\
\hline & $\begin{array}{c}<65 \text { Years } \\
\text { (n 176) }\end{array}$ & $\begin{array}{c}\geq 65 \text { Years } \\
(\mathrm{n} \mathrm{103})\end{array}$ & $p$ & $\begin{array}{c}<65 \text { Years } \\
\text { (n 177) }\end{array}$ & $\begin{array}{c}\geq 65 \text { Years } \\
\text { (n 127) }\end{array}$ & $p$ \\
\hline Arrhythmias & 1.1 & 10.7 & $<0.0001$ & 4.0 & 5.5 & 0.523 \\
\hline Heart failure & 1.1 & 2.9 & 0.280 & 2.8 & 3.1 & 0.869 \\
\hline \multicolumn{7}{|l|}{ Antihyperglycaemic agent: } \\
\hline Metformin & 81.3 & 85.4 & 0.371 & 87.6 & 90.6 & 0.416 \\
\hline Sulphonylureas or glinides & 15.9 & 23.3 & 0.126 & 11.9 & 7.1 & 0.168 \\
\hline Pioglitazone & 0.6 & 2.9 & 0.112 & 1.7 & 4.7 & 0.124 \\
\hline GLP-1 receptor agonist & 34.7 & 28.2 & 0.262 & 63.3 & 58.3 & 0.377 \\
\hline Insulin & 37.5 & 39.8 & 0.702 & 39.0 & 46.5 & 0.193 \\
\hline SGLT-2i & 0 & 0 & & 100 & 100 & NA \\
\hline Dapagliflozin $10 \mathrm{mg}$ & & & & 47.7 & 49.6 & \\
\hline Canagliflozin $100 \mathrm{mg}$ & & & & 29.5 & 28.3 & \\
\hline Empagliflozin $10 \mathrm{mg}$ & & & & 5.1 & 9.4 & \\
\hline Empagliflozin 25 mg & & & & 10.8 & 1 & \\
\hline Antihypertensive drugs & 61.4 & 80.7 & 0.004 & 76.8 & 81.1 & 0.007 \\
\hline Lipid-lowering drugs & 70.5 & 81.6 & 0.165 & 84.7 & 91.3 & 0.124 \\
\hline
\end{tabular}

Data: percentage or mean (SD), except * median (IQR). BMI: Body Mass Index. DBP: diastolic blood pressure. eGFR: estimated glomerular filtrate rate. SBP: systolic blood pressure. 
Table 2. Safety outcomes.

\begin{tabular}{|c|c|c|c|c|}
\hline & \multicolumn{2}{|c|}{ CANA100 } & \multicolumn{2}{|c|}{ CANA 300} \\
\hline & $\begin{array}{c}<65 \text { Years } \\
\quad(n \text { 176) }\end{array}$ & $\begin{array}{l}\geq 65 \text { Years } \\
\quad(n \text { 103) }\end{array}$ & $\begin{array}{c}<65 \text { Years } \\
\text { (n 177) }\end{array}$ & $\begin{array}{c}\geq 65 \text { Years } \\
\text { (n 127) }\end{array}$ \\
\hline Withdrawals $(\%) *$ & 12 & 8.7 & 9 & 9.4 \\
\hline Deaths (\%) & 1 & 0 & 0 & 0 \\
\hline \multicolumn{5}{|l|}{ AEs of special interest } \\
\hline Genital mycotic infections (\%) & 13 & 9.7 & 10.2 & 7.9 \\
\hline Urinary tract infections (\%) & 4.5 & 4.9 & 5.6 & 9.4 \\
\hline Hypoglycaemias (\%) & 7.4 & 9.7 & 6.2 & 13.4 \\
\hline Intravascular volume-related AEs (\%) & 1.1 & 1.9 & 0 & 0.8 \\
\hline Fractures (\%) & 0.6 & 1.9 & 0 & 0 \\
\hline Polycythaemia (\%) & 1.7 & 0 & 1.1 & 0.8 \\
\hline Ketoacidosis $(\%)$ & 0 & 0 & 0 & 0 \\
\hline Amputations (\%) & 0 & 0 & 0 & 0 \\
\hline
\end{tabular}

Differences between age groups were not statistically significant, except for hypoglycaemias in the CANA300 cohort $(p<0.033)$. AEs: Adverse Events. * Withdrawals in the CANA100 cohort other than switching to CANA300.

The main outcomes were to assess changes in $\mathrm{HbA} 1 \mathrm{c}$ from V1 to V2 and V3 in both cohorts of CANA100 and CANA300, and to compare these results between subgroups of participants younger than 65 and aged 65 and older. Secondary outcomes were to assess changes in weight, eGFR, microalbuminuria, lipid profile, BP, liver function tests, hematocrit, and serum uric acid, and to compare these results between subgroups of participants younger than 65 and aged 65 and older.

\subsection{Statistical Methods}

Results are shown as mean (standard deviation [SD]) (continuous variables that follow a normal distribution) or as median (interquartile range [IQR]) (those that do not meet normality criteria). Categorical data are shown in percentages. Analyses were carried out using the available data without any imputation of missing data. McNemar tests, Paired t-tests and Wilcoxon tests were performed to compare baseline data to that at followup. A multiple linear regression analysis was performed to assess the adjusted mean differences between older and younger patients, controlling for those baseline variables with statistically significant differences between both age groups.

All analyses were conducted by using 2-sided tests and a significance level of 0.05 with the Statistical Package for the Social Sciences (SPSS) version 15.0.1 (IBM Corp., Armonk, NY, USA).

\section{Results}

\subsection{Demographic and Baseline Characteristics}

A total of 583 patients met the inclusion criteria (230 (60.5\%) $\geq 65$ years, $33(5.7 \%)$ $>75$ years), 279 in the cohort of CANA100 (men $54.8 \%$, mean age 59.7 years, 36.9\% >65 years, mean $\mathrm{HbA} 1 \mathrm{c} 8.05 \%$, mean BMI $34.8 \mathrm{~kg} / \mathrm{m}^{2}$ ) and 304 in the cohort of CANA300 (men $55.9 \%$, mean age 61.1 years, $41.8 \% \geq 65$ years, mean $\mathrm{HbA} 1 \mathrm{c} 7.51 \%$, mean BMI $\left.34.5 \mathrm{~kg} / \mathrm{m}^{2}\right)$. Baseline characteristics of the patients from different age groups and canagliflozin dose groups are shown in Table 1.

In both cohorts, patients aged $\geq 65$ years showed a longer T2DM duration, lower BMI, higher prevalence of high BP (in the CANA100 cohort) and hyperlipidaemias, as a more advanced chronic kidney disease (CKD).

\subsection{Analyses of Effectiveness}

In the CANA100 cohort (median follow-up 9.2 months), patients aged $\geq 65$ years showed significant reductions in $\mathrm{HbA} 1 \mathrm{c}$ at V2 and V3 $(-0.70 \%$ [95\% CI -0.44 to -0.93 ] and $-0.78 \%$ [ $95 \% \mathrm{CI}-0.55$ to -1$]$, respectively, both $p<0.0001$ ), and the percentage of 
patients with $\mathrm{HbA} 1 \mathrm{c}$ below $7 \%$ significantly increased from $23.8 \%$ at V1 to $49.5 \%$ at V3 $(p<0.0001)$. Patients younger than 65 years showed significant reductions in HbA1c at V2 and V3 ( $-1.06 \%$ [95\% CI -0.73 to -1.39 ] and $-0.97 \%$ [95\% CI -0.72 to -1.21 ] respectively, both $p<0.0001$ ), and the percentage of patients with $\mathrm{HbA1c}$ below $7 \%$ significantly increased from $26 \%$ at V1 to $51.2 \%$ at V3 ( $p<0.0001)$.

In the subgroup of patients aged $\geq 65$ years with suboptimal glycaemic control, defined as baseline $\mathrm{HbA} 1 \mathrm{c}>7 \%$ (mean $\mathrm{HbA1c} 8.48 \%$ ), CANA100 decreased $\mathrm{HbA} 1 \mathrm{c}$ at V2 and V3 $(-0.83 \%$ [95\% CI -0.53 to -1.1 ] and $-1.0 \%$ [95\% CI -0.73 to -1.2 ] respectively, both $p<0.0001)$. In those patients with poor glycaemic control, defined as baseline $\mathrm{HbA} 1 \mathrm{c}>8 \%$ (mean HbA1c 9.1\%) CANA100 decreased HbA1c at V2 and V3 (-1\% [95\% CI - 0.62 to -1.5 ] and $-1.3 \%$ [95\% CI -0.91 to -1.7$]$ respectively, both $p<0.0001)$.

CANA100 was associated with a significant weight loss (WL) in older patients at V2 and V3 $(-3.9 \mathrm{~kg}[95 \% \mathrm{CI}-0.67$ to -2.6$]$ and $-4.5 \mathrm{~kg}[95 \% \mathrm{CI}-2.9$ to -6$]$ respectively, both $p<0.0001)$. In younger patients, CANA100 was associated with a significant WL at V2 and V3 $(-3.62 \mathrm{~kg}[95 \% \mathrm{CI}-2.62$ to -4.63$]$ and $-3.79 \mathrm{~kg}$ [95\% CI -2.87 to -4.71$]$ respectively, both $p<0.0001)$.

In addition, in the CANA100 cohort, older patients showed a non-significant reduction in SBP $(-4.6 \mathrm{mmHg})$ and a significant decrease in DBP at V3 $(-2.4 \mathrm{~mm} \mathrm{Hg}[95 \% \mathrm{CI}-0.23$ to -4.5$], p<0.05)$.

In those individuals with SBP > $140 \mathrm{mmHg}$ at V1 (mean SBP $155 \mathrm{mmHg}$ ), CANA100 lowered SBP levels at V3 by -16.1 and $-14.1 \mathrm{mmHg}$ in older and younger patients, respectively (both $p<0.0001$ ).

In the multivariate analysis, after controlling for duration of T2DM, estimated glomerular filtration rate (eGFR), weight, A1c, HTA and dyslipidaemia, and adjusted differences in HbA1c reduction, WL and $\mathrm{BP}$ changes between both age groups were not statistically significant.

In the CANA300 cohort (median follow-up 14 months), patients aged $\geq 65$ years showed, starting from a median $\mathrm{HbA} 1 \mathrm{c} 7.58 \%$ at $\mathrm{V} 1$, significant reductions in $\mathrm{HbA} 1 \mathrm{c}$ at $\mathrm{V} 2$ and V3 $(-0.36 \%$ [95\% CI -0.04 to -0.17 ] and $-0.27 \%$ [95\% CI -0.07 to -0.11 ] respectively, both $p<0.0001$ ). The percentage of patients with $\mathrm{HbA} 1 \mathrm{c}$ below 7\% significantly increased from $23.6 \%$ at V1 to $40.7 \%$ at V3 ( $p<0.0001$ ). Patients younger than 65 years showed, starting from a median $\mathrm{HbA} 1 \mathrm{c} 7.48 \%$ at $\mathrm{V} 1$, significant reductions in $\mathrm{HbA} 1 \mathrm{c}$ at V2 and V3 $(-0.51 \%$ [95\% CI -0.34 to -0.68$]$ and $-0.40 \%$ [95\% CI -0.22 to -0.58$]$ respectively, both $p<0.0001$ ). The percentage of patients with $\mathrm{HbA} 1 \mathrm{c}$ below $7 \%$ significantly increased from $32.8 \%$ at $\mathrm{V} 1$ to $50.9 \%$ at V3 $(p<0.0001)$.

In the subgroup of patients aged $\geq 65$ years with suboptimal glycaemic control, defined as baseline $\mathrm{HbA} 1 \mathrm{c}>7 \%$ (mean $\mathrm{HbA} 1 \mathrm{c} 8.1 \%$ ), CANA300 significantly decreased HbA1c at V2 and V3 $(-0.42 \%$ [95\% CI -0.20 to -0.64 ] and $-0.39 \%$ [95\% CI -0.20 to -0.58 ] respectively, both $p<0.0001)$. In those patients with poor glycaemic control, defined as baseline $\mathrm{HbA} 1 \mathrm{c}>8 \%$ (mean $\mathrm{HbA} 1 \mathrm{c} 9.13 \%$ ), CANA300 significantly lowered HbA1c at V2 and V3 $(-0.92 \%$ [95\% CI -0.51 to -1.3$]$ and $-0.91 \%$ [95\% CI -0.53 to -1.3 ] respectively, both $p<0.0001)$. In the multivariate analysis, the adjusted differences in $\mathrm{HbA1c}$ reduction between both age groups were not statistically significant.

CANA300 was associated with significant WL in the older patient group at V2 and V3 $(-2 \mathrm{~kg}$ [95\% CI -1.1 to -2.8$]$ and $2.1 \mathrm{~kg}$ [95\% CI -1.1 to -3$]$ respectively, both $p<0.0001)$. In younger patients, CANA300 significantly lowered the body weight at V2 and V3 $(-2.14 \mathrm{~kg}$ [95\% CI -1.41 to -2.87 ] and $-2.15 \mathrm{~kg}$ [95\% CI -1.18 to -3.13 ] respectively, both $p<0.0001)$.

There was a numerical reduction in SBP $(-3.0 \mathrm{mmHg})$ and DBP $(-1.8 \mathrm{mmHg})$ at the end of the follow-up period in older patients, without reaching statistical significance. In those patients with SBP > $140 \mathrm{mmHg}$ at V1 (mean SBP $153 \mathrm{mmHg}$ ), CANA300 lowered SBP levels at V3 by -15.4 and $-16.2 \mathrm{mmHg}$ in older and younger patients, respectively (both $p<0.0001$ ).

In the multivariate analysis, after controlling for duration of T2DM, eGFR, weight, A1c, HTA and dyslipidaemia, smoking and coronary heart disease, and the adjusted 
differences in $\mathrm{HbA} 1 \mathrm{c}$ reduction, weight loss and $\mathrm{BP}$ changes between both age groups were not statistically significant.

\subsection{Analyses of Safety}

In the CANA100 cohort, drug discontinuation was $36.9 \%$ and $48.9 \%$ in older and younger patients, respectively, over the entire follow-up period (Table 2). The main reason leading to CANA100 discontinuation in both age groups was switching to CANA300: $28.2 \%$ in older and $36.9 \%$ in younger patients $(76.3 \%$ and $75.6 \%$, respectively, of the whole discontinuation in both groups). Other reasons were GMIs $(2.9 \%)$, UTIs $(1.0 \%)$ and the worsening of kidney function (1.0\%). No significant differences in withdrawals were observed between both age groups.

In the older age group, the most common AEs with CANA100 were GMI (9.7\%), UTI (4.9\%), mild hypoglycaemia (9.7\%), intravascular volume-related AEs $(1.9 \%)$, and fractures $(1.9 \%)$, without significant differences with younger patients. No amputations, polyglobulia or ketoacidosis were reported.

In the CANA300 cohort, drug discontinuation rates were similar in both age groups ( $9.4 \%$ and $9.0 \%$ in older and younger patients, respectively) (Table 2). The main AEs leading to WD of CANA300 in patients aged $\geq 65$ years were UTIs $(2.4 \%)$, GMIs $(0.8 \%)$, and the worsening of kidney function $(0.8 \%)$.

A total of $7.9 \%$ of patients $\geq 65$ years experienced GMIs, $9.4 \%$ experienced UTI, $13.4 \%$ experienced mild hypoglycaemia, $0.8 \%$ experienced polycythaemia, and $0.8 \%$ experienced intravascular volume-related AEs, without significant differences with younger patients, except a higher frequency of hypoglycaemias. No fractures, ketoacidosis or amputations were reported.

\section{Discussion}

Findings from this observational, retrospective, multicentre study show that CANA100 improved glycaemic control and reduced body weight and BP in patients with T2DM younger than 65 , and aged 65 and older, without statistically significant differences between both age groups. In addition, switching to CANA300 from prior CANA100 or other SGLT2 is is associated with statistically significant $\mathrm{HbA} 1 \mathrm{c}$ and weight reduction and improved SBP, regardless of age groups.

Regarding the effects of canagliflozin in older adults with T2DM, there is a RCT in individuals with T2DM aged 55 to 80 years comparing canagliflozin to a placebo [18], and a longer 78-week extension report of this same study [19]. Both of them showed that canagliflozin improved glycaemic control, reduced body weight and SBP, and was generally well tolerated. However, there were no data about possible differences with younger patients.

There are also some pooled analyses of 26-week, placebo-controlled phase 3 RCTs with canagliflozin, comparing individuals aged 65 years and older with younger patients [20,21], showing a similar decrease in $\mathrm{HbA1c}$ and BMI, although smaller HbA1c reductions in older participants with baseline eGFR 45 to $<60 \mathrm{~mL} / \mathrm{min} / \mathrm{m}^{2}$. In patients aged 75 and older, a pooled analysis of placebo-controlled randomised phase 3 studies of 18-26 weeks of duration found a lower numerical reduction in HbA1c efficacy of canagliflozin in older participants [22], possibly related to their lower mean baseline eGFR and a higher incidence of AEs.

While RCTs report clinical outcomes in controlled settings, such results may not be generalisable to patients seen in clinical practice, and RW, although statistically less rigorous, can provide valuable insight into how AHA perform within specific subgroups (such as older patients) often excluded in RCTs. We have identified some retrospective RWS with canagliflozin in older patients ( $\geq 65$ years) [23-26], but in most of them the study design does not allow for the comparison of clinical outcomes with younger patients, except the study by Johnson et al. [25], which found smaller HbA1c reductions in older patients. Those results need to be interpreted with caution, due to the small sample size of 
the older subgroup (66 patients) and the short follow-up period (mean time to last visit 215 days).

There are also some subanalyses from cardiovascular RCTs with empagliflozin and dapagliflozin $[27,28]$ which show the cardio-renal benefits and safety of these SGLT-2is, regardless of age.

Our study compared two age groups (230 patients in the older cohort) from the same population with a median follow-up of around a year, in a real setting. Outcomes of our study show that the improvements with CANA100 therapy in glucose control, BP and weight previously described in this same population of patients with T2DM [17], in accordance with other RCT or RWS, are kept in older patients. Even the observation of greater reductions in $\mathrm{HbA1c}$ seen among those patients receiving canagliflozin, who had a higher baseline $\mathrm{HbA} 1 \mathrm{c}$, is a feature independent of age.

The results of our study in relation to changes in $\mathrm{HbA} 1 \mathrm{c}(-0.78 \%)$ are in accordance with those described in RWS and pooled analysis in older patients with canagliflozin therapy [20-26]. Although younger patients showed numerically higher reduction in $\mathrm{HbA1c}$ than older ones, this was not a statistically significant difference, in contrast to the report from Johnson et al. [25] with a smaller sample size and shorter follow-up period than our study.

As previously mentioned, [22] reported data about patients aged 75 years and older. In our population, this subset of patients was only $5.7 \%$ and the comparison with younger patients did not show any statistically significant result.

We found several differences in baseline characteristics between age groups in both cohorts, such as a longer duration of T2DM and, therefore, more comorbidities as high BP (in the CANA100 cohort), CKD, heart disease or hyperlipidaemia are not surprising. On the other hand, the observed lower BMI is a common finding in people of advanced age for several reasons (loss of muscle mass, reduced energy intake, etc.). In summary, there were not any unexpected baseline differences between age groups.

Canagliflozin-reduced efficacy occasionally reported in the elderly may be a consequence of an age-dependent decline in estimated glomerular filtration rate (eGFR) rather than ageing per se, as has been described in some studies [22,29]. Pooled analyses by Gilbert et al. [21] only observed $\mathrm{HbA} 1 \mathrm{c}$ reduction differences between age groups in the subset of participants with baseline eGFR 45 to $<60 \mathrm{~mL} / \mathrm{min} / 1.73 \mathrm{~m}^{2}$. In our study, despite a lower baseline eGFR in older patients, we did not observe any difference between age groups improving glycaemic control.

In relation to the strategy of intensification of CANA300 from other SGLT-2is not previously tested in this age group, we observed an additional $\mathrm{HbA} 1 \mathrm{c}$ and weight reduction, raising the percentage of patients in good glycaemic control (HbA1c below $7 \%$ ) from $23.6 \%$ to $40.7 \%$, without age-related differences. In this case, improvement in $\mathrm{HbA} 1 \mathrm{c}$ and weight was modest compared to that observed in the CANA100 cohort, but we should take into account that significant reductions in $\mathrm{HbA} 1 \mathrm{c}$ and weight had already been attained with prior SGLT-2is therapy before the switch. In fact, HbA1c at V1 in the CANA300 cohort was $7.58 \%$.

A reduction of SBP has been previously reported in older patients in canagliflozin therapy $[15,16,18-22]$. In our study, this effect was more relevant in the subset of patients with bad blood pressure control (SBP $>140 \mathrm{~mm} \mathrm{Hg}$ ). In this setting, both cohorts (CANA100 and CANA300) showed a statistically significant reduction, above $15 \mathrm{~mm} \mathrm{Hg}$ in older patients, contributing to adequate blood pressure control. Larger reductions in DBP observed in the CANA100 cohort in older versus younger patients may be explained by more volume depletion in older patients [21,25].

The safety analysis was consistent with the findings observed in other RCTs [30] or RWS [31], and similar to the results of previous clinical studies of canagliflozin in elderly patients with T2DM [26]. The overall incidence of AEs with canagliflozin in our study was low, with most being mild or moderate in severity, but without differences between the two age groups. In fact, drug discontinuation rates were numerically more frequent in younger 
than older patients in the CANA100 cohort. A higher rate of non-severe hypoglycaemia in older patients in the CANA300 cohort may be in relation to numerically more people being treated with insulin in this group. Nevertheless, special attention is needed to prevent hypoglycaemia in elderly patients, because severe hypoglycaemia is more likely to occur in these patients. An appropriate dose adjustment of insulin preparations and/or insulin secretagogues should be considered to prevent hypoglycaemia when using these drugs concomitantly with SGLT-2is.

Limitations of this study included the retrospective study design, which did not allow for control of the sample bias, but we have compared the results with the younger patients from the same sample. In addition, information on some variables was not recorded at each office visit, which resulted in missing data in some analyses. There is a potential recall bias in the frequency of AEs, as they were collected retrospectively. However, systematic research through electronic databases from primary care, laboratory departments and emergency departments was conducted to collect unreported AEs. The study design was not powered to find differences between age subgroups.

Additionally, this descriptive analysis did not control for other factors, such as the initiation of treatment with other medications, that might have contributed to the changes in body weight and BP observed over the course of the study. Since some AHAs were modified (either increased or decreased) over the follow-up period, especially in the CANA100 cohort, some influence of these changes on the final outcomes cannot be excluded.

It is also important to acknowledge that the results from this study may not be generalisable to broader populations because the sample in this study was selected from endocrinology clinics with generally more advanced T2DM (as disease duration and number of diabetes medications showed) than those from primary care settings.

Despite these limitations, the findings from the present study supplement the evidence on real-world outcomes with canagliflozin in the over-65 population with T2DM.

\section{Conclusions}

In summary, CANA100 (as an add-on therapy) and CANA300 (switching from CANA100 or other SGLT-2is) in patients with T2DM in a real-world setting showed similar effectiveness and safety, regardless of age. This subanalysis confirms the results of previous RCTs and RWS in older patients and adds real-life evidence on the strategy of switching to CANA300 from prior SGLT-2 therapy in that age group. Together, these findings support canagliflozin (CANA100 as an add-on therapy, or switching to CANA300 from other SGLT-2is) as a safe and effective therapeutic option for the increasingly frequent patients with T2DM older than 65 years or more, and contributes to clinicians feeling more confident to prescribe CANA to older patients with T2DM.

Author Contributions: All authors participated in the design, data collection, data interpretation, and critical review of the article. J.J.G.-M. performed the statistical analysis. M.A.G.-F. wrote the manuscript. All authors have read and agreed to the published version of the manuscript.

Funding: This research received no external funding.

Institutional Review Board Statement: The study was approved by the Ethical Review Boards (ethic code 19/56) of the centers which took part in the study and was performed in compliance with the ethical guidelines for research on humans. All the procedures were in accordance with the requirements set out in the international standards for epidemiological studies, as recorded in the International Guidelines for Ethical Review of Epidemiological Studies, and with the Helsinki Declaration of 1964, as revised in 2013. For this type of study, individual consent was not required.

Informed Consent Statement: Patient consent was waived due to retrospective data collection.

Data Availability Statement: The datasets generated during and/or analysed during the current study are available from the corresponding author on reasonable request.

Conflicts of Interest: M.A.G.-F. has the following financial relationships: lectures for Almirall SA, Astra-Zeneca, Boehringer Ingelheim Pharmaceuticals Inc., Janssen Pharmaceuticals, Eli Lilly and 
Company, Novo-Nordisk, and Sanofi-Aventis; conducts research activities for Almirall SA, AstraZeneca, and Sanofi-Aventis. A.G.S.-P. has the following financial relationships: advisor on scientific boards for Astra-Zeneca and Janssen Pharmaceuticals; lectures for Astra-Zeneca, Boehringer Ingelheim Pharmaceuticals Inc., Janssen Pharmaceuticals, Eli Lilly and Company, Novo-Nordisk, Mundipharma Pharmaceuticals, Abbott, and Sanofi-Aventis. T.A.-B. has the following financial relationships: lectures for Astra-Zeneca, Mundipharma, Novo-Nordisk, Janssen Pharmaceuticals, Esteve, Eli Lilly and Company, and Sanofi-Aventis. M.B.-S. has the following financial relationships: advisor on scientific boards for Astra-Zeneca, Janssen Pharmaceuticals, Merck Sharp and Dohme, Novo-Nordisk, and Sanofi-Aventis; lectures for Almirall SA, Astra-Zeneca, Boehringer Ingelheim Pharmaceuticals Inc., Esteve, FAES, Eli Lilly and Company, Merck Sharp and Dohme, Mylan, NovoNordisk, and Sanofi-Aventis. J.J.G.-M. has the following financial relationships: advisor on scientific boards for Astra-Zeneca, Janssen Pharmaceuticals, Eli Lilly and Company, Merck Sharp and Dohme, and Novo-Nordisk; lectures for Abbott, AbbVie Inc., Astra-Zeneca, Boehringer Ingelheim Pharmaceuticals Inc., Esteve, Janssen Pharmaceuticals, Eli Lilly and Company, Merck Sharp and Dohme, Novo-Nordisk, Roche Pharma, and Sanofi-Aventis; conducts research activities for Astra-Zeneca and Sanofi-Aventis. J.W.-C. has no relevant financial interests to report.

\section{References}

1. $\quad$ Leroith, D.; Biessels, G.J.; Braithwaite, S.S.; Casanueva, F.F.; Draznin, B.; Halter, J.B.; Hirsch, I.B.; McDonnell, M.; Molitch, M.E.; Murad, M.H.; et al. Treatment of Diabetes in Older Adults: An Endocrine Society Clinical Practice Guideline. J. Clin. Endocrinol. Metab. 2019, 104, 1520-1574. [CrossRef]

2. Gomez-Huelgas, R.; Peralta, F.G.; Mañas, L.R.; Formiga, F.; Domingo, M.P.; Bravo, J.M.; Miranda, C.; Ena, J. Tratamiento de la diabetes mellitus tipo 2 en el paciente anciano. Rev. Clin. Esp. 2018, 218, 74-88. [CrossRef]

3. Sinclair, A.; Morley, J.E.; Rodríguez-Mañas, L.; Paolisso, G.; Bayer, A.; Zeyfang, A.; Bourdel-Marchasson, I.; Vischer, U.; Woo, J.; Chapman, I.; et al. Diabetes Mellitus in Older People: Position Statement on behalf of the International Association of Gerontology and Geriatrics (IAGG), the European Diabetes Working Party for Older People (EDWPOP), and the International Task Force of Experts in Diabetes. J. Am. Med. Dir. Assoc. 2012, 13, 497-502. [CrossRef]

4. Reyes-García, R.; Moreno-Pérez, O.; Tejera-Pérez, C.; Fernández-García, D.; Bellido-Castañeda, V.; de la Torre Casares, M.L.; Rozas-Moreno, P.; Fernández-García, J.C.; Marco Martínez, A.; Escalada-San Martín, J.; et al. En representación del Grupo de trabajo de Diabetes-SEEN. Document on a comprehensive approach to type 2 diabetes mellitus. Documento de abordaje integral de la diabetes tipo 2. Endocrinol. Diabetes Nutr. 2019, 66, 443-458. [CrossRef]

5. Kirkman, M.S.; Briscoe, V.J.; Clark, N.; Florez, H.; Haas, L.B.; Halter, J.B.; Huang, E.S.; Korytkowski, M.T.; Munshi, M.N.; Odegard, P.S.; et al. Diabetes in older adults: A consensus report. J. Am. Geriatr. Soc. 2012, 60, 2342-2356. [CrossRef]

6. Zaccardi, F.; Webb, D.R.; Htike, Z.Z.; Youssef, D.; Khunti, K.; Davies, M. Efficacy and safety of sodium-glucose co-transporter-2 inhibitors in type 2 diabetes mellitus: Systematic review and network meta-analysis. Diabetes Obes. Metab. 2016, 18, 783-794. [CrossRef]

7. Thomas, M.C.C.; Cherney, D.Z. The actions of SGLT2 inhibitors on metabolism, renal function and blood pressure. Diabetologia 2018, 61, 2098-2107. [CrossRef]

8. Chilton, R.J. Effects of sodium-glucose cotransporter-2 inhibitors on the cardiovascular and renal complications of type 2 diabetes. Diabetes Obes. Metab. 2020, 22, 16-29. [CrossRef]

9. Devineni, D.D.; Curtin, C.R.; Polidori, D.; Gutierrez, M.J.; Murphy, J.; Rusch, S.; Rothenberg, P.L. Pharmacokinetics and pharmacodynamics of canagliflozin, a sodium glucose co-transporter 2 inhibitor, in subjects with type 2 diabetes mellitus. J. Clin. Pharmacol. 2013, 53, 601-610. [CrossRef]

10. Stenlöf, K.; Cefalu, W.T.; Kim, K.A.; Alba, M.; Usiskin, K.; Tong, C.; Canovatchel, W.; Meininger, G. Efficacy and safety of canagliflozin monotherapy in subjects with type 2 diabetes mellitus inadequately controlled with diet and exercise. Diabetes Obes. Metab. 2013, 15, 372-382. [CrossRef]

11. Forst, T.; Guthrie, R.; Goldenberg, R.; Yee, J.; Vijapurkar, U.; Meininger, G.; Stein, P. Efficacy and safety of canagliflozin over 52 weeks in patients with type 2 diabetes on background metformin and pioglitazone. Diabetes Obes. Metab. 2014, 16, 467-477. [CrossRef] [PubMed]

12. Devineni, D.; Morrow, L.; Hompesch, M.; Skee, D.; Vandebosch, A.; Murphy, J.; Ways, K.; Schwartz, S. Canagliflozin improves glycemic control over 28 days in subjects with type 2 diabetes not optimally controlled on insulin. Diabetes Obes. Metab. 2012, 14, 539-545. [CrossRef] [PubMed]

13. Fulcher, G.; Matthews, D.R.; Perkovic, V.; de Zeeuw, D.; Mahaffey, K.W.; Mathieu, C.; Woo, V.; Wysham, C.; Capuano, G.; Desai, M.; et al. Efficacy and safety of canagliflozin when used in conjunction with incretin-mimetic therapy in patients with type 2 diabetes. Diabetes Obes. Metab. 2016, 18, 82-91. [CrossRef] [PubMed]

14. Perkovic, V.; Jardine, M.J.; Neal, B.; Bompoint, S.; Heerspink, H.J.L.; Charytan, D.M.; Edwards, R.; Agarwal, R.; Bakris, G.; Bull, S.; et al. Canagliflozin and Renal Outcomes in Type 2 Diabetes and Nephropathy. N. Engl. J. Med. 2019, 380, 2295-2306. [CrossRef] [PubMed] 
15. Neal, B.; Perkovic, V.; Mahaffey, K.W.; De Zeeuw, D.; Fulcher, G.; Erondu, N.; Shaw, W.; Law, G.; Desai, M.; Matthews, D.R. Canagliflozin and Cardiovascular and Renal Events in Type 2 Diabetes. N. Engl. J. Med. 2017, 377, 644-657. [CrossRef] [PubMed]

16. Jardine, M.J.; Mahaffey, K.W.; Neal, B.; Agarwal, R.; Bakris, G.L.; Brenner, B.M.; Bull, S.; Cannon, C.P.; Charytan, D.M.; de Zeeuw, D.; et al. The Canagliflozin and Renal Endpoints in Diabetes with Established Nephropathy Clinical Evaluation (CREDENCE) Study Rationale, Design, and Baseline Characteristics. Am. J. Nephrol. 2017, 46, 462-472. [CrossRef] [PubMed]

17. Gorgojo-Martínez, J.J.; Gargallo-Fernández, M.A.; Galdón Sanz-Pastor, A.; Antón-Bravo, T.; Brito-Sanfiel, M.; Wong-Cruz, J. Real-World Clinical Outcomes Associated with Canagliflozin in Patients with Type 2 Diabetes Mellitus in Spain: The Real-Wecan Study. J. Clin. Med. 2020, 9, 2275. [CrossRef] [PubMed]

18. Bode, B.; Stenlöf, K.; Sullivan, D.; Fung, A.; Usiskin, K. Efficacy and safety of canagliflozin treatment in older subjects with type 2 diabetes mellitus: A randomized trial. Hosp. Pract. 2013, 41, 72-84. [CrossRef]

19. Bode, B.; Stenlöf, K.; Harris, S.; Sullivan, D.; Fung, A.; Usiskin, K.; Meininger, G. Long-term efficacy and safety of canagliflozin over 104 weeks in patients aged 55 to 80 years with type 2 diabetes. Diabetes Obes. Metab. 2015, 17, 294-303. [CrossRef]

20. Sinclair, A.; Bode, B.; Harris, S.; Vijapurkar, U.; Mayer, C.; Fung, A.; Shaw, W.; Usiskin, K.; Desai, M.; Meininger, G. Efficacy and safety of canagliflozin compared with placebo in older patients with type 2 diabetes mellitus: A pooled analysis of clinical studies. BMC Endocr. Disord. 2014, 14, 37. [CrossRef]

21. Gilbert, R.E.; Weir, M.R.; Fioretto, P.; Law, G.; Desai, M.; Kline, I.; Shaw, W.; Meininger, G. Impact of Age and Estimated Glomerular Filtration Rate on the Glycemic Efficacy and Safety of Canagliflozin: A Pooled Analysis of Clinical Studies. Can. J. Diabetes 2016, 40, 247-257. [CrossRef] [PubMed]

22. Sinclair, A.J.; Bode, B.; Harris, S.; Vijapurkar, U.; Shaw, W.; Desai, M.; Meininger, G. Efficacy and Safety of Canagliflozin in Individuals Aged 75 and Older with Type 2 Diabetes Mellitus: A Pooled Analysis. J. Am. Geriatr. Soc. 2016, 64, 543-552. [CrossRef] [PubMed]

23. Meckley, L.; Miyasato, G.; Kokkotos, F.; Bumbaugh, J.; Bailey, R. An observational study of glycemic control in canagliflozin treated patients. Curr. Med. Res. Opin. 2015, 31, 1479-1486. [CrossRef]

24. Bailey, R.A.; Schwab, P.; Xu, Y.; Pasquale, M.; Renda, A. Glycemic Control Outcomes after Canagliflozin Initiation: Observations in a Medicare and Commercial Managed Care Population in Clinical Practice. Clin. Ther. 2016, 38, 2046-2057.e2. [CrossRef]

25. Johnson, J.F.; Parsa, R.; Bailey, R.A. Real-world Clinical Outcomes Among Patients with Type 2 Diabetes Receiving Canagliflozin at a Specialty Diabetes Clinic: Subgroup Analysis by Baseline $\mathrm{HbA}_{1 \mathrm{c}}$ and Age. Clin Ther. 2017, 39, 1123-1131. [CrossRef]

26. Goda, M.; Yamakura, T.; Sasaki, K.; Tajima, T.; Ueno, M. Safety and efficacy of canagliflozin in elderly patients with type 2 diabetes mellitus: A 1-year post-marketing surveillance in Japan. Curr. Med. Res. Opin. 2017, 34, 319-327. [CrossRef]

27. Monteiro, P.; Bergenstal, R.M.; Toural, E.; Inzucchi, S.E.; Zinman, B.; Hantel, S.; Kiš, S.G.; Kaspers, S.; George, J.T.; Fitchett, D. Efficacy and safety of empagliflozin in older patients in the EMPA-REG OUTCOME®trial. Age Ageing 2019, 48, 859-866. [CrossRef]

28. Cahn, A.; Mosenzon, O.; Wiviott, S.D.; Rozenberg, A.; Yanuv, I.; Goodrich, E.; Murphy, S.A.; Bhatt, D.L.; Leiter, L.A.; McGuire, D.K.; et al. Efficacy and Safety of Dapagliflozin in the Elderly: Analysis From the DECLARE-TIMI 58 Study. Diabetes Care 2019, 43, 468-475. [CrossRef]

29. Yamout, H.; Perkovic, V.; Davies, M.; Woo, V.; De Zeeuw, D.; Mayer, C.; Vijapurkar, U.; Kline, I.; Usiskin, K.; Meininger, G.; et al. Efficacy and Safety of Canagliflozin in Patients with Type 2 Diabetes and Stage 3 Nephropathy. Am. J. Nephrol. 2014, 40, 64-74. [CrossRef] [PubMed]

30. Rosenthal, N.; Meininger, G.; Ways, K.; Polidori, D.; Desai, M.J.; Qiu, R.; Alba, M.; Vercruysse, F.; Balis, D.A.; Shaw, W.; et al. Canagliflozin: A sodium glucose co-transporter 2 inhibitor for the treatment of type 2 diabetes mellitus. Ann. N. Y. Acad. Sci. 2015, 1358, 28-43. [CrossRef]

31. Woo, V.; Bell, A.; Clement, M.; Noronha, L.; Tsoukas, M.; Camacho, F.; Traina, S.; Georgijev, N.; Culham, M.D.; Rose, J.B.; et al. CANadian CAnagliflozin REgistry: Effectiveness and safety of canagliflozin in the treatment of type 2 diabetes mellitus in Canadian clinical practice. Diabetes Obes. Metab. 2018, 21, 691-699. [CrossRef] [PubMed] 